\title{
Percepções de gestores sobre competências gerenciais em diferentes contextos: estabilidade e mudança organizacional
}

\author{
Managers perceptions about their competences in different contexts: \\ stability and organizational change
}

André Luís Janzkovski Cardoso

Mestre em Administração de Empresas, head of services operations \& excellence latin america da Siemens Enterprise Communications GmbH \& Co, Curitiba, PR - Brasil, e-mail: cardoso9778@gmail.com

\section{Resumo}

Este estudo buscou compreender como os gestores avaliam as suas competências em dois diferentes cenários: estabilidade e mudança organizacional. Foi realizada uma pesquisa quantitativa por meio de um questionário construído a partir da revisão do referencial teórico e de outras pesquisas no âmbito das competências gerenciais. A cada respondente foi solicitado indicar sua atitude para cada um dos 46 atributos de competências nas situações de estabilidade e mudança, assim como o grau de importância de cada um desses itens. Foram recebidas 56 respostas válidas. O objetivo principal foi verificar se há diferenças de percepções quanto às competências gerenciais nos dois contextos, assim como se fatores como escolaridade e tempo de experiência influenciariam nas percepções dos gestores. Os resultados indicam haver diferenças de percepções da maioria dos participantes com respeito à utilização de suas competências nos diferentes contextos. Apenas as competências "criatividade e inovação" e "carreira" apresentam-se com maior intensidade em situações de mudança e todas as demais são indicadas a serem mais utilizadas nas situações de estabilidade. Adicionalmente, a hipótese da influência do nível de escolaridade é reforçada, o que não ocorre quanto à influência do tempo de experiência gerencial.

Palavras-chave: Competências gerenciais. Estabilidade. Mudança organizacional. 


\begin{abstract}
This study searches to understand how managers evaluate their competences in two different scenarios: stability and organizational change. A quantitative research based on a questionnaire constructed after reviewing the scientific researches in the scope of the management competences was carried through. To each respondent it was requested to indicate its attitude for each one of the 46 items for both contexts stability and change, as well as the degree of importance of each of these items. 56 answers was received and considered valid. The main objective was to verify if it has differences of perceptions in the two contexts, as well as if factors as degree of study and time of management experience they would influence in the perceptions of the managers. The results indicate to have differences of perceptions of the majority of the participants with respect to the use of their competences in the two different contexts. Competences as "creativity and innovation" and "career" have presented themselves with higher intensity in organization change situation and all others have been indicated to be more used in the stability situation. Additionally, the hypothesis about the positive influence of degree of study is strengthened, nevertheless the influence of management experience is not.
\end{abstract}

Keywords: Management competences. Stability. Organizational change.

\section{Introdução}

No contexto contemporâneo, a única certeza é que a mudança é contínua e cada vez mais acelerada. Diante do processo de globalização, observam-se mudanças nos campos político, econômico, social e principalmente organizacional.

No panorama político-econômico há um enfraquecimento de economias seculares e o surgimento de novas potências econômicas, porém, com maiores propensões a turbulências em razão da estrutura de interdependência entre os mercados nas diversas economias mundiais. Há por um lado uma forte influência dos Estados na regulamentação de práticas protecionistas, contudo, por outro lado, com uma necessidade de se criar alianças estratégicas, como a União Europeia, a Alca e o Mercosul.

No campo social há mudanças consideráveis quanto à socialização e democratização do uso da internet e à preocupação, ao menos latente, com os desequilíbrios sociais, com tendência a se discutir uma nova relação entre classes sociais.

No âmbito das organizações, enfrenta-se concorrência agressiva, crescimento na consolidação de empresas por meio de fusões e aquisições, rapidez no surgimento e na obsolescência de novas tecnologias, dinamismo nas comunicações e nas trocas de dados dentro e entre empresas, potencializando desafios de controle e garantia de confidencialidade das informações estratégicas. Há também modificação do perfil dos empregados e dos clientes, principalmente pela migração da indústria de manufatura para a de serviços, requerendo com isso uma completa revisão do modus operandi das organizações em todo o mundo. Conviver com mudanças não é uma situação opcional, pois as organizações pouco controlam o ambiente externo e tentam buscar mecanismos para atuar na incerteza, fortalecendo seu ambiente interno e se preparando para enfrentar seus principais concorrentes com agilidade, consistência e melhores práticas. Para enfrentar tais desafios em uma sociedade do conhecimento cuja grande riqueza está no capital humano e em seu intelecto, muitas organizações estão estruturando processos de gestão de competências como uma das iniciativas para responder coerentemente às mudanças e alcançar uma posição que lhes garanta alguma vantagem competitiva sustentável.

Definir competência por si só já se apresenta como um grande desafio para pesquisadores e organizações que buscam se estruturar e praticar a gestão por competência como uma forma de obter vantagens competitivas. Alguns autores questionam os modelos em prática, indicando inconsistência e falta de entendimento comum, mas isso não diminuia intensificação da utilização de diversos modelos pelas empresas e consultorias. Autores como Robotham e Jubb (1996) indicam a existência de mitos sobre o tema desenvolvimento de competências. Tais autores criticam as indefinições sobre o que é competência, se a eficiência gerencial pode ser definida e medida, quão generalizável pode ser o modelo de competência gerencial, como relacionar os planos de treinamento com o desenvolvimento de competências 
e a consequente obtenção de melhores resultados. Contudo, há consenso de que pesquisas acadêmicas e trabalhos empíricos devem ser realizados para comprovar, ou não, a eficiência e os benefícios dos modelos de competência e gestão.

Dentre o conjunto de competências de uma organização, especial atenção é dada às competências gerenciais por serem os gestores considerados elementos fundamentais na concretização das estratégias de suas organizações.

No vasto universo de conceitos, teorias e práticas presentes na bibliografia sobre o tema competência e no âmbito das competências individuais, este trabalho concentrou esforços na condução de um estudo empírico para responder ao problema de pesquisa de como os gestores avaliam as suas competências em dois diferentes cenários: estabilidade e mudança organizacional. O objetivo principal do estudo foi compreender como os gestores avaliam as suas competências em dois diferentes cenários, buscando:

- depreender as percepções de gestores sobre como colocam em prática os atributos de competência nas situações de estabilidade e mudança organizacional;

- identificar quais competências são mais utilizadas em cada um dos contextos; e - identificar se há diferenças de percepções em função da experiência gerencial e do nível de escolaridade.

Para este estudo as seguintes hipóteses foram consideradas:

- hipótese 1: há alteração, na percepção dos gestores, do conjunto de competências praticadas entre as situações de estabilidade e mudança;

- bipótese 2: o nível de escolaridade é um dos fatores demográficos que influencia a percepção dos gestores sobre o conjunto de competência praticado;

- hipótese 3: há relação direta entre tempo de experiência gerencial e a percepção do conjunto de competências em cada uma das duas situações de estabilidade e mudança.

À luz de trabalhos anteriores, tendo como suporte as linhas de pensamento de pesquisadores americanos, europeus e brasileiros, optou-se por utilizar uma modelagem quantitativa baseada na construção e aplicação de um questionário de atributos de competências e a consequente análise dos dados por meio dos modelos estatísticos.

\section{Referencial teórico}

O termo competência tem sido utilizado desde a idade média, sendo na época vinculado à linguagem jurídica, indicando a faculdade atribuída a alguém para julgar questões. Desde então, esse termo é utilizado para referendar socialmente a pessoa que é capaz de se pronunciar sobre determinado assunto. Com a revolução industrial e a concepção taylorista, esse termo passa a ser utilizado indicando pessoas capazes de desempenhar determinado papel ou atividade operacionalmente definida. A partir da década de 1970, muitos autores foram se especializando no tema e propondo definições próprias e vários estudos passaram a ser realizados por duas correntes principais. A primeira, constituída por estudiosos norte-americanos (BOYATZIS, 1982; McLELLAND, 1973), identificando competência como a interação entre conhecimentos, habilidades e atitudes de uma pessoa que é qualificada para a realização de um determinado trabalho; e, por estudiosos anglo-saxões (CHEETHAM; CHIVERS, 1996, 1998), tendo como referencial o modelo de competências desenvolvido pelo governo britânico. A segunda, representada principalmente por autores franceses (LE BOTERF, 1999; ZARIFIAN, 1999), entendendo competência como as realizações e a entrega de valor do indivíduo em determinado contexto profissional.

Um dos primeiros pesquisadores no assunto, McClelland (1973), desenvolveu uma técnica, denominada entrevista de comportamento eventual, que consistia de perguntas abertas situacionais. Os entrevistados eram solicitados a contar os detalhes relativos a um determinado evento, suas ações, os resultados alcançados e como a pessoa se sentiu e, com isso, objetivava-se predizer quais dos candidatos teriam mais possibilidades de desempenhar um papel específico. Para o autor, competência está associada à sensibilidade ao contexto. Outro importante pesquisador, Boyatzis (1982), propôs um modelo integrado envolvendo as demandas do trabalho, ambiente organizacional em que o trabalho 
é realizado e as competências do indivíduo. Segundo esse autor, competência representa a capacidade do indivíduo aplicada no contexto do trabalho e que produz uma ação efetiva.

A colaboração europeia amplia os conceitos propostos pela escola americana, incluindo novas variáveis para a definição do conceito de competência. Segundo Le Boterf (1999, p. 48), "o profissional competente não é aquele que possui conhecimentos ou habilidades, mas aquele que sabe mobilizá-los em um contexto profissional". Para esse autor, o bom profissional é aquele que sabe dominar uma técnica e executá-la bem mesmo em um contexto de competitividade e estresse. Nesse ponto há duas importantes contribuições: a primeira é a de que a competência só se realiza na ação, ou seja, quando de fato acontece; e a segunda é a de que essa ação na prática acontece sob a influência de uma determinada situação.

De acordo com Zarifian (1999, p. 56):

o retorno do trabalho à competência do indivíduo que o exerce coloca, simultaneamente, a variabilidade e a "evolutibilidade" das próprias ações profissionais, em razão não unicamente da variabilidade das situações, mas também do entendimento que o indivíduo e a rede de trabalho na qual está inserido podem ter das situações profissionais em dado momento.

Dessa forma, o autor entende que o indivíduo é agente e determina, por meio do seu entendimento e da sua compreensão, qual o sentido e a dimensão do seu trabalho.

Zarifian (1999) e Le Boterf (1999) identificam o contexto ou a situação como um elemento importante na análise de competência e na relação entre o ambiente de trabalho, o posicionamento do agente executor da atividade, a disponibilidade de informações e as capacidades mentais, cognitivas e afetivas que o levam a uma interpretação diferente da mesma realidade. A perspectiva do indivíduo é um diferencial. Outro ponto de concordância entre esses dois autores é que o profissional competente é aquele que sabe selecionar os elementos necessários no repertório de recursos, apesar de suas heterogeneidades e multiplicidades, e de forma consciente trabalhá-los para realizar uma atividade profissional alinhada com os objetivos da organização.

Dentre os autores brasileiros, Carbone (2006, p. 42) postula que competência é materializada pelo "desempenho expresso pela pessoa em determinado contexto, em termos de comportamentos e realizações decorrentes da mobilização e aplicação de conhecimentos, habilidades e atitudes no trabalho". $\mathrm{O}$ autor propõe entender competências humanas como combinações sinérgicas, de conhecimentos, habilidades e atitudes, expressas pelo desempenho profissional dentro de determinado contexto organizacional e que agregam valor a pessoas e organizações (CARBONE, 2006, p. 43).

Dutra (2001) postula que uma pessoa é competente quando, a partir das suas capacidades, entrega e agrega valor à organização em que atua, a ele próprio e à sociedade em que vive. Entende-se por essa ótica que a questão de agregar valor, ou produzir algum serviço ou atividade de valor, deve ser reconhecida por terceiros, membros da organização, pela sociedade e pelo próprio indivíduo que a produz ou executa tal como uma autorrealização.

Um conceito que inter-relaciona ação, capacidades humanas, recursos e contexto é apresentado por Ruas (2005), indicando que "um conceito de competência, que define que a ação conseqüente é aquela que mobiliza, integra e prioriza recursos segundo as condições da situação ou contexto, estabelece a capacidade de flexibilidade e adaptação como um de seus elementos essenciais" (RUAS, 2005 , p. 52). Ou seja, a combinação eficiente dos recursos, influenciada pelas condições de cada situação ou evento, é ingrediente para a concretização do trabalho, e o valor gerado pelo resultado dessa ação determina a competência.

Uma proposta de categorização aceita no meio acadêmico indica que competências em uma organização podem ser definidas como as essenciais, as coletivas e as individuais. Prahalad e Hamel (2000) indicam que as competências essenciais são aquelas decorrentes do aprendizado coletivo da organização e estão diretamente associadas à estruturação do trabalho e à entrega de valor. São distinguidas quando levam a organização ao acesso potencial e à ampla variedade de mercados (oportunidade), contribuem de maneira significativa nos benefícios percebidos pelos clientes (inovação) e são difíceis de ser imitadas no curto prazo (diferenciação). Segundo Weick (1993, apud BONOTTO; BITENCOURT, 2006, p. 2), as competências coletivas (visão pluralista) têm sua origem no processo de sensemaking de um grupo e na habilidade desse grupo em "dar sentido" e produzir ações. De acordo com esse autor, elas 
constituem a construção de uma identidade que é explorada nos processos de interação com outras pessoas, construindo o sentido de uma situação, e ocorrem em três níveis:

1) intersubjetivo: quando o sentido é criado com base na interação dos indivíduos;

2) genérico: o sentido é criado com base em normas, procedimentos, etc.;

3) extrassubjetivo: quando se atingiu um nível de realidade simbólica de puro significado (comparável à cultura).

Bonotto e Bitencourt (2006) postulam que

competências coletivas podem ser entendidas como a capacidade de um grupo de pessoas atingir um objetivo comum, tendo como base uma visão compartilhada construída a partir da qualidade dos processos de interação entre as pessoas, do contexto e do sentido que essas pessoas conferem ao grupo è̀s suas atividades" (BONOTTO; BITENCOURT, 2006, p. 1).

Segundo Dutra (2001), as competências individuais podem ser definidas pela combinação de conhecimentos, habilidades, atitudes e recursos que, colocados em prática por um indivíduo em um determinado contexto, produzem um resultado de valor. Já quanto às competências gerenciais, contidas no conjunto das competências individuais, Le Boterf (2003, p. 56) postula que "o bom gestor não é aquele que aplica em qualquer circunstância o mesmo comportamento: ele sabe modular sua estratégia de gerenciamento em função das situações que encontra". Complementarmente, o autor indica que "a plasticidade está no coração da competência [...] não é uma constante" (LE BOTERF, 2003, p. 52). Essa proposição sugere que a competência deve variar em função da alteração da situação e do contexto.

Uma justificativa relevante desse campo é fortalecida por Fleury e Fleury (2006, p. 247):

além de construir uma instância fundamental nos processos de mudança tendo em vista o papel da liderança, a dimensão competência gerencial exerce também uma importante função na mobilização das outras dimensões das competências organizacionais: essen- ciais (âmbito organização como um todo), funcionais (áreas da empresa e grupos) e individuais.

Um importante aspecto nos estudos sobre competência se dá com respeito à sua forma de mensuração. Competência é etérea, tornando seu estudo e mensuração ainda mais complexos. Faz-se necessário operacionalizar uma forma de mensuração objetiva por meio de construtos concretos. McLagan (1997) indica que uma das formas de se definir competência (abstrato) seria por meio de uma coleção de atributos que fossem observáveis na prática e pudessem ser avaliados (concreto).

Zarifian (2001) propõe que é possível construir referências de competências tendo por base categorias de situações, mas menciona a dificuldade de se definir completamente a dimensão de evento das situações. Quanto à composição da competência, Fleury e Fleury (2006, p. 249) advertem que "é preciso que se entenda que caracterizar os recursos de competências não é uma tarefa fácil tendo em vista a sua heterogeneidade, complexidade e suas dimensões mais abstratas".

Colaborando na sugestão de alternativas de mensuração, Carbone (2006) indica que "competências são mais bem descritas por meio de atributos de comportamentos observáveis na prática no ambiente de trabalho e que são passíveis de mensuração [...] desta forma o desempenho representa uma expressão, uma manifestação da competência" (CARBONE, 2006, p. 56).

No entanto, Ruas (2005) alerta que, apesar da dimensão competência individual (e gerencial por estar nela incluída) ser a mais conhecida e difundida, observações empíricas têm mostrado que a noção de competência individual carrega consigo uma grande heterogeneidade de percepções e conceitos nos ambientes empresariais.

Como um dos interesses deste estudo é a percepção dos gestores em situação de mudança organizacional, há a necessidade de relacionar liderança e mudança. Dentre as diversas mudanças que uma organização pode passar, uma das mais complexas é a mudança de sua cultura. Schein (1992) indica que a cultura é fortemente transmitida pelos fundadores e líderes e que o processo de aprendizado relativo à formação dos pressupostos nada mais é do que uma doutrinação dos novos integrantes da organização. Complementa o autor que esse processo é uma 
forma de fortalecer as condutas comportamentais que residem na mente dos líderes e fundadores, as quais, por terem sucesso, são tidas como válidas e corretas. $\mathrm{O}$ autor entende que a participação do líder é fundamental, tanto na criação, disseminação e transformação da cultura, bem como na maneira de reagir a incidentes críticos e às crises e mudanças organizacionais. Para Schein (1992), um bom líder é aquele que consegue controlar a ansiedade do grupo diante das situações críticas, oferecendo, também, soluções para problemas que venham a ocorrer durante a operação do negócio.

O modelo de gestão e aprendizagem proposto por Kolb (1997) estabelece quatro etapas de um processo cíclico: 1) experiência concreta; 2) observações e reflexões; 3) formação de conceitos abstratos e generalizados; e 4) testes de implicações dos conceitos em novas situações. Segundo o autor, é possível compreender como o indivíduo utiliza - da sua experiência - os conceitos, as regras e os princípios como norteadores nas ações em situações novas, e como ele modifica essas práticas para melhorar a eficácia (torna-se mais competente).

No ambiente organizacional, os gestores enfrentam novos desafios e situações e utilizamse das experiências anteriores, dos resultados produzidos na solução de outros problemas, nos aprendizados passados para agir e tomar suas decisões. Esse processo cíclico de aprendizagem e desenvolvimento depende muito mais da riqueza e da variedade das experiências vividas e do poder de reflexão e concepção de conceitos do que do tempo de atuação em uma determinada área. Isso reforça a indicação de Winterton e Winterton (1999) de que o desenvolvimento de competências depende mais de critérios qualitativos delineados pela interação entre aprendizado cognitivo e emocional, os estágios de carreira e as diferentes formas de aprendizado ocupacionais.

As dimensões tempo e espaço são fundamentais no desenvolvimento de competências coletivas. O tempo é o elemento que determina experiência, conhecimento tácito e experiência prática; e o espaço (ambiente e contexto) é a mais importante dimensão da competência interpessoal, onde acontece a interação. Com esse embasamento teórico, entende-se que os gestores influenciam e atuam nas mudanças organizacionais por meio de suas condutas, práticas, atitudes, valores e competências gerenciais.
Este trabalho considerou que as competências gerenciais são reveladas pelo uso eficiente dos recursos próprios (conhecimento, habilidades, atitudes, experiências e interesses) e dos recursos da organização (físicos, monetários e humanos), ajustando-se ao contexto e adaptando-se às mudanças de forma estruturada e buscando obter resultados de valor. Todavia, o foco estará em identificar os atributos de competências e suas variações nos contexto de estabilidade e mudança para um grupo de gestores e não em "qualificar o estágio" de competência de cada indivíduo em particular.

\section{Estudos e pesquisas anteriores}

Tão importante quanto as revisões literárias, fundamentais no estudo acadêmico, são as revisões críticas de trabalhos já publicados na área de interesse e a localização de campos pouco explorados ou de novas oportunidades para estudos, a fim de ampliar o conhecimento já produzido. Com essa clara e convicta intenção foram revisados diversos trabalhos empíricos, identificando os modelos utilizados, sua estruturação, pontos convergentes e divergentes e as descobertas de seus autores.

Hunt e Laing (1997) realizaram uma pesquisa com 105 executivos seniores e coletaram a percepção destes sobre seus pares, identificando características da liderança exemplar. Essas características foram agrupadas em 11 competências, nas dimensões cognitiva, interpessoal, apresentação e motivacional, e indicam que os profissionais que assim as executam são os de mais elevado desempenho.

Outro estudo foi desenvolvido por Klemp Jr. (1999), que, a partir da análise de 62 modelos de competências de lideranças de grandes empresas mundiais, buscou identificar quais práticas e atributos pessoais eram mais desejáveis em líderes dessas empresas, o que resultou no "modelo dos nove baldes". A principal reflexão desse autor é na identificação entre dois tipos de competências: práticas, indicando o que as pessoas efetivamente fazem, por meio de suas funções, para produzir determinado resultado; e atributos, sendo os conhecimentos, as técnicas e as habilidades que as pessoas trazem para a função elhes permitem exercer as tarefas de liderança. O autor indica que "os atributos são a matéria-prima do desempenho. São as habilidades necessárias para 
exercer a função. As práticas são atitudes tomadas a partir dos próprios atributos" (KLEMP Jr., 1999, p. 134). Na visão do autor, as práticas dependem dos atributos, mas os atributos não garantem por si só a efetividade na prática. Ele complementa ainda que $65 \%$ das empresas pesquisadas adotam modelos mistos (práticas e atributos), 27\%, modelos que priorizam as práticas e $8 \%$, modelos que priorizam os atributos. O motivo para essa relação é fortalecido pela descoberta de que os executivos referem-se a seus pares como pessoas que "além de 'ter as qualidades certas, fazem as coisas certas" (KLEMP Jr., 1999, p. 134). O Quadro 1 indica os resultados consolidados pelo autor, cujos valores percentuais demonstram a presença dos atributos e das práticas nos modelos pesquisados.

Outros artigos internacionais abordam o tema "competências" sob óticas demográficas. Dentre eles, McGregor e Tweed (2001) utilizam uma tipologia de 54 competências gerenciais em uma pesquisa com 363 empresários e gerentes de empresas de manufatura da Nova Zelândia, tentando identificar características que individualizassem percepções de homens e mulheres. A análise dos dados comprovou que os atributos de competências utilizados no estudo representavam as competências gerenciais para ambos os sexos, sem indicar diferenças significativas, e ainda demonstrou a efetividade da lista de competências.

\begin{tabular}{llll}
\hline Principais atributos & & Principais práticas & $64 \%$ \\
\hline Integridade / sinceridade / ética & $77 \%$ & Desenvolver pessoas & $55 \%$ \\
Capacidade de realização & $76 \%$ & Obter resultados & $52 \%$ \\
Habilidade de lidar com pessoas & $73 \%$ & Concentrar-se no cliente & $52 \%$ \\
Orientação para o aprendizado & $73 \%$ & Comunicar-se & $46 \%$ \\
Capacidade de direcionar e controlar & $66 \%$ & Orientar a visão e a direção & $43 \%$ \\
Capacidade de influenciar pessoas & $64 \%$ & Criar laços de relacionamento comercial & $41 \%$ \\
Raciocínio estratégico & $64 \%$ & Tomar decisões & $39 \%$ \\
Compreensão de conceitos & $63 \%$ & Gerenciar o desempenho & $38 \%$ \\
Flexibilidade / adaptabilidade & $61 \%$ & Influenciar a organização & $36 \%$ \\
Autoconfiança / coragem & $60 \%$ & Cooperar / participar de equipes & $36 \%$ \\
Iniciativa / orientação para a ação & $58 \%$ & Criar equipes & $34 \%$ \\
Capacidade de comunicação & $52 \%$ & Desenvolver soluções criativas & $32 \%$ \\
Energia / entusiasmo & $50 \%$ & Criar um ambiente de alto desempenho & $32 \%$ \\
Habilidade política & $50 \%$ & Impulsionar mudanças & $29 \%$ \\
Cooperação & $48 \%$ & Ser um modelo de sua função & $29 \%$ \\
Raciocínio analítico & $48 \%$ & Gerenciar a diversidade / valorizar o outro & $25 \%$ \\
Responsabilidade / comprometimento & $48 \%$ & Desenvolver estratégias & $23 \%$ \\
Capacidade de julgamento & $44 \%$ & Assumir responsabilidade pelas coisas & \\
Capacidade de tomar decisões & $44 \%$ & & \\
Conhecimento do negócio & $40 \%$ & & \\
\hline
\end{tabular}

Quadro 1 - Atributos e práticas do gestor por percentual de incidência Fonte: Adaptado de KLEMP Jr., 1999. 
Oderich (2001) faz uma revisão teórica de diversos estudos envolvendo competências individuais, gerenciais e de líderes e formula um modelo do perfil do gestor com 9 competências-chave. Dentre os trabalhos citados, incluem-se os estudos de Bower (1999), no livro Talentopara liderar, onde há a identificação de um conjunto de atributos de líderes, adotando a premissa de que um gestor é um líder, podendo ser utilizado como outro mapa de competências.

Um trabalho realizado por Kilimnik et al. (2004) utilizou uma pesquisa de campo para identificar percepções de pós-graduados e pós-graduandos acerca das competências profissionais e da modernidade das políticas de gestão das organizações em que atuavam. Um conjunto de 15 competências foi avaliado por meio de uma escala Likert e houve predominância de respostas nos três últimos pontos da escala $(8,9$ e 10$)$, indicando elevada demanda por essas competências, conforme visão dos entrevistados.

O Anexo 1 indica a relação entre as competências identificadas pelos autores e, na última coluna à direita, as competências que serão utilizadas neste estudo. Realizadas as etapas de revisão da literatura e análise dos trabalhos publicados, foram identificadas nove competências-chave, são elas: liderança, persuasão/negociação, trabalho em equipe, criatividade/inovação, tomada de decisão/ solução de problemas, planejamento/organização, determinação/motivação, autodesenvolvimento/ aprendizagem e personalidade.

\section{Metodologia}

A metodologia utilizada teve como base o método quantitativo, com coleta de dados por meio de questionário enviado a 70 gestores pertencentes a diversas áreas de uma empresa multinacional de origem alemã, com sede no Brasil, atuante na área de telecomunicações. A seleção desses participantes utilizou o método não probabilístico, com amostragem por conveniência, e o perfil necessário e condicional para participar do estudo foi atuar em posição de liderança.

O objetivo da pesquisa foi verificar se há diferenças de percepções quanto às competências gerenciais nos dois contextos, estabilidade e mudança, assim como se fatores como escolaridade e tempo de experiência influenciariam nas percepções dos gestores. O conjunto de variáveis deste estudo pode ser divido em variáveis demográficas (formação, formação complementar, idade, tempo de empresa, experiência gerencial, número de funcionários diretos, indiretos, área de atuação e localidade), conforme Anexo 2, e variáveis numéricas, de acordo com a percepção de cada indivíduo acerca dos 46 atributos (duas situações) e o grau de importância, conforme Anexo 3.

A pesquisa solicitava aos respondentes que indicassem a percepção de sua atuação em cada um dos 46 atributos de competência, em dois contextos distintos (estabilidade e mudança organizacional), por meio de uma escala Likert de 5 pontos, assim como indicar para cada um dos atributos qual o nível de importância com índices, variando de $1=$ nada importante a $5=$ extremamente importante, conforme Quadro 2.

O método de pesquisa utilizado foi o quantitativo, por meio da coleta de dados, utilizando-se de questionário e tratamento dos dados com modelos estatísticos de análise fatorial e regressão linear.

A partir da definição das competências de interesse neste estudo, buscou-se a elaboração de um instrumento que pudesse identificar as variações nos níveis de utilização dessas competências por meio de atributos de competência. A partir da revisão do referencial teórico teve início a elaboração de um questionário que identificasse e pudesse operacionalizar e medir o construto "competências gerenciais". Para operacionalizar e conceituar as dimensões desse construto foram considerados alguns trabalhos já desenvolvidos anteriormente e as áreas comuns entre suas principais contribuições e descobertas.

Segundo sugere Hair (2006), uma sequência de passos deve ser seguida para se definir os itens de cada construto e as escalas de mensuração. A primeira etapa foi a definição do conceito a ser medido e quais componentes desse conceito (abstrato) seriam operacionalizados em itens observáveis. A partir de estudos prévios foi possível construir uma lista de atributos de competências que representam as competências gerenciais por meio de atitudes e comportamentos observáveis na prática.

A etapa seguinte foi um processo de avaliação da validade interna por meio da aplicação do questionário a especialistas (alunos, professores e membros da população a ser pesquisada). Conforme descrito no Diagrama 1, a partir da modelagem da primeira lista com 45 atributos de competências esta foi enviada a alunos do curso de mestrado para que 


\begin{tabular}{|c|c|c|c|c|}
\hline \multicolumn{5}{|c|}{ Como você se percebe em cada um dos atributos abaixo em duas situações distintas: } \\
\hline \multicolumn{5}{|c|}{ situação de estabilidade organizacional } \\
\hline 0 a $25 \%$ & $26 \%$ a $50 \%$ & $51 \%$ a $75 \%$ & $76 \%$ a $95 \%$ & $>95 \%$ \\
\hline quase nunca & poucas vezes & muitas vezes & quase sempre & sempre \\
\hline \multicolumn{5}{|c|}{ situação de mudança organizacional } \\
\hline 0 a $25 \%$ & $26 \%$ a $50 \%$ & $51 \%$ a $75 \%$ & $76 \%$ a $95 \%$ & $>95 \%$ \\
\hline quase nunca & poucas vezes & muitas vezes & quase sempre & sempre \\
\hline
\end{tabular}

Quadro 2 - Escala Likert 5 pontos e grau de importância (1-5)

Fonte: Dados da pesquisa.

identificassem a qual competência os itens estariam relacionados (uma ou mais) como processo de análise de conteúdo. Os mestrandos receberam a lista com 45 itens e tiveram que classificá-los como pertencentes às nove competências ou indicar a opção "outra". A mesma solicitação foi feita a dois especialistas da área de competências e a um especialista da área de metodologia quantitativa, buscando a confirmação da representatividade dos itens e a análise semântica destes. Este processo resultou na identificação de 46 atributos e, após a seleção da escala de mensuração (Likert 5 pontos), o instrumento de mensuração estava definido. Ainda como uma forma de validade interna, o questionário foi aplicado a cinco membros do público-alvo da pesquisa como uma forma de verificação do entendimento das questões, de possíveis dificuldades e dúvidas no preenchimento. O questionário revisado e validado por membros da amostra foi enviado aos demais participantes.

Dos 70 questionários enviados, foram recebidos 57 respondidos (taxa de retorno de 81\%), dos quais 56 foram considerados válidos. No total cada respondente indicou sua resposta a 147 itens. Após a consolidação dos dados em um arquivo único, utilizou-se o software SPSS para tratamento e análise dos dados (software Statistical Package of Social Sciences - SPSS).

Segundo Hair (2006), há a necessidade de se obter uma amostra mínima de cinco vezes o número de variáveis do modelo. Esse importante aspecto tornaria inviável a aplicação da análise fatorial a este estudo, tendo em vista o número de respondentes de 56 e o número de variáveis de 46 (por situação). Contudo, uma estratégia utilizada neste estudo foi a de definir previamente um conjunto de itens para cada uma das nove competências inicialmente definidas e com isso foi aplicada a análise fatorial individual para cada competência. Dessa forma fica garantido o critério de amostra mínima, pois como o número de itens por competência variava de 4 a 7 , os 56 respondentes representaram uma amostra estatisticamente relevante.

A etapa seguinte foi a análise da confiabilidade. Nesse processo busca-se garantir a confiabilidade de coerência interna por meio do alfa de Cronbach's, conforme indicado por Hair (2006). Para coeficientes entre 0,6 e 0,7, a intensidade de associação dos itens é moderada; entre 0,7 e 0,8 é boa; entre 0,8 e 0,9 , muito boa; e acima de 0,9 , excelente. O Diagrama 1 indica todas as etapas da pesquisa.

\section{Análise dos dados}

Primeiramente, foram trabalhados os dados da estatística descritiva para as variáveis demográficas e os resultados estão indicados no Quadro 3.

A análise fatorial individual considerou o uso do coeficiente KMO (índice de Kaiser, Meyer, Olkin), Bartlett's Test of Sphericity e anti-image para a matriz de correlação, fator de extração com eigenvalues acima de 1, uso de scree plot e rotação varimax. Os resultados individuais foram trabalhados e validados por meio do alfa de Cronbach's de forma a obter o menor número de fatores que explicassem a maior variância dos dados nos dois contextos (estabilidade e mudança). O objetivo foi minimizar a quantidade de fatores e maximizar a variância total explicada, 
tendo como referência mínima $50 \%$ de variância explicada e o alfa de Cronbach's superior a 0,7. Os dados da análise fatorial estão dispostos na Tabela 1 , incluindo as sugestões de nomes dos fatores de competências consolidadas.

Das nove competências iniciais e dos 46 atributos, os dados revelaram a necessidade de se criar uma nova categoria que, nesse caso, foi denominada de "carreira". Houve a eliminação de dez itens, pois não se apresentaram significativos na análise dos dados. A composição dos itens para as dez competências, assim como a média das percepções do uso dos atributos de competências em cada uma das duas situações, está demonstrada na Tabela 2. Os dados apresentados foram a consolidação das respostas de todos os respondentes nas situações de estabilidade (estab.) e mudança (mud.), a média do grau de importância de cada atributo de competência (import.). Os valores delta foram a diferença entre mudança e estabilidade e o item "fator" é a média ponderada entre os atributos de competência e seus respectivos graus de importância.

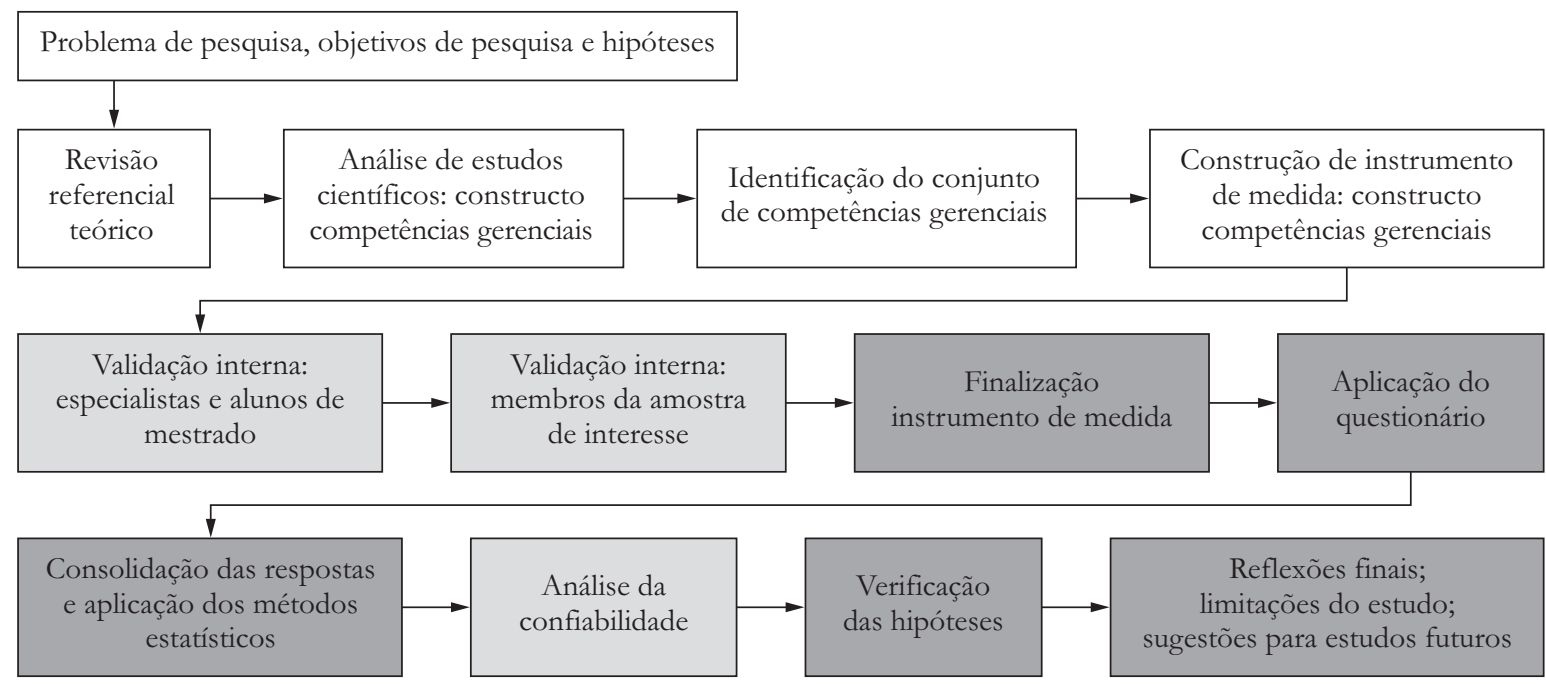

$\square$ Definição do problema de pesquisa até a identificação do constructo

$\square$ Critérios de qualidade: validação interna e confiabilidade

$\square$ Processo de pesquisa: coleta e análise dos dados e conclusões

Diagrama 1 - Todas as etapas da pesquisa

Fonte: Dados da pesquisa.

\begin{tabular}{llllll}
\hline Respondentes & Escolaridade & Idade média & $\begin{array}{l}\text { Tempo de } \\
\text { empresa } \\
\text { (médio) }\end{array}$ & $\begin{array}{l}\text { Experiência } \\
\text { gerencial } \\
\text { (média) }\end{array}$ & $\begin{array}{l}\text { Senioridade } \\
\text { gerencial }\end{array}$ \\
\hline 56 & 32 pós-graduação & 39 anos & 16 anos & 6 anos & 28 abaixo de 5 anos 37 área central \\
& $223^{\circ}$ grau completo & & 28 acima de 5 anos 19 filiais \\
& $2 \quad 3^{\circ}$ grau andamento & & & \\
\hline
\end{tabular}

Quadro 3 - Estatística descritiva das variáveis demográficas

Fonte: Dados da pesquisa. 
Tabela 1 - Dados após análise fatorial - recomposição dos itens

\begin{tabular}{|c|c|c|c|c|c|c|c|c|c|c|c|}
\hline \multicolumn{2}{|l|}{$\begin{array}{l}\text { Análise fatorial - } \\
\text { Resultado final }\end{array}$} & \multicolumn{5}{|c|}{ Estabilidade } & \multicolumn{5}{|c|}{ Mudança } \\
\hline Fator & Item & KMO & SIG & ALFA & VAR & VAR Total & KMO & SIG & ALFA & VAR & VAR Total \\
\hline \multirow[t]{3}{*}{ Liderança } & 1 & 0,729 & 0,000 & 0,704 & $41,43 \%$ & $59,27 \%$ & 0,773 & 0,000 & 0,742 & $44,24 \%$ & $59,83 \%$ \\
\hline & 5 & & & & & & & & & & \\
\hline & 6 & & & & & & & & & & \\
\hline \multirow{3}{*}{$\begin{array}{l}\text { Planejamento e } \\
\text { organização }\end{array}$} & 29 & & & & $17,84 \%$ & & & & & $15,59 \%$ & \\
\hline & 30 & & & & & & & & & & \\
\hline & 46 & & & & & & & & & & \\
\hline \multirow{4}{*}{$\begin{array}{l}\text { Persuasão e } \\
\text { negociação }\end{array}$} & 9 & 0,796 & 0,000 & 0,785 & $38,35 \%$ & $56,07 \%$ & 0,757 & 0,000 & 0,760 & $36,61 \%$ & $57,61 \%$ \\
\hline & 10 & & & & & & & & & & \\
\hline & 11 & & & & & & & & & & \\
\hline & 12 & & & & & & & & & & \\
\hline \multirow{5}{*}{$\begin{array}{l}\text { Criatividade } \\
\text { e inovação }\end{array}$} & 18 & & & & $17,71 \%$ & & & & & $21,00 \%$ & \\
\hline & 19 & & & & & & & & & & \\
\hline & 20 & & & & & & & & & & \\
\hline & 21 & & & & & & & & & & \\
\hline & 22 & & & & & & & & & & \\
\hline \multirow[t]{4}{*}{ Trabalho em equipe } & 13 & 0,678 & 0,000 & 0,700 & $53,42 \%$ & $53,42 \%$ & 0,723 & 0,000 & 0,736 & $56,00 \%$ & $56,00 \%$ \\
\hline & 14 & & & & & & & & & & \\
\hline & 42 & & & & & & & & & & \\
\hline & 43 & & & & & & & & & & \\
\hline \multirow{3}{*}{$\begin{array}{l}\text { Autodesenvolvimento } \\
\text { e aprendizagem }\end{array}$} & 16 & 0,706 & 0,000 & 0,733 & $47,52 \%$ & $66,56 \%$ & 0,723 & 0,000 & 0,781 & $48,15 \%$ & $66,43 \%$ \\
\hline & 36 & & & & & & & & & & \\
\hline & 37 & & & & & & & & & & \\
\hline \multirow[t]{3}{*}{ Carreira } & 38 & & & & $19,04 \%$ & & & & & $18,28 \%$ & \\
\hline & 39 & & & & & & & & & & \\
\hline & 40 & & & & & & & & & & \\
\hline \multirow{4}{*}{$\begin{array}{l}\text { Tomada de } \\
\text { decisão e solução } \\
\text { de problemas }\end{array}$} & 15 & 0,733 & 0,000 & 0,715 & $37,94 \%$ & $52,82 \%$ & 0,749 & 0,000 & 0,726 & $38,67 \%$ & $52,96 \%$ \\
\hline & 23 & & & & & & & & & & \\
\hline & 24 & & & & & & & & & & \\
\hline & 25 & & & & & & & & & & \\
\hline \multirow[t]{3}{*}{ Personalidade } & 26 & & & & $14,88 \%$ & & & & & $14,29 \%$ & \\
\hline & 27 & & & & & & & & & & \\
\hline & 45 & & & & & & & & & & \\
\hline \multirow{4}{*}{$\begin{array}{l}\text { Determinação e } \\
\text { motivação }\end{array}$} & 32 & 0,759 & 0,000 & 0,761 & $58,85 \%$ & $58,85 \%$ & 0,739 & 0,000 & 0,763 & $59,41 \%$ & $59,41 \%$ \\
\hline & 33 & & & & & & & & & & \\
\hline & 34 & & & & & & & & & & \\
\hline & 35 & & & & & & & & & & \\
\hline
\end{tabular}

Fonte: Dados da pesquisa. 
Tabela 2 - Dados após análise fatorial - recomposição dos itens e identificação da variação das médias das percepções de uso dos atributos de competências

(Continua)

\begin{tabular}{|c|c|c|c|c|c|c|c|}
\hline Competências & Item & Atributo de competência & Estab. & Mud. & Import. & Delta & Fator \\
\hline \multirow[t]{3}{*}{ Liderança } & 1 & $\begin{array}{l}\text { Transmito bem a missão e os objetivos da } \\
\text { organizacão a meus subordinados }\end{array}$ & 3,95 & 3,75 & 4,50 & $-0,20$ & \multirow[t]{3}{*}{$-0,21$} \\
\hline & 5 & Direciono as atividades das equipes & 4,00 & 4,16 & 3,88 & 0,16 & \\
\hline & 6 & Atuo como coach ou mentor na minha equipe & 3,91 & 3,77 & 4,36 & $-0,14$ & \\
\hline \multirow{3}{*}{$\begin{array}{l}\text { Planejamento e } \\
\text { organização }\end{array}$} & 29 & Traço estratégia para atingir resultados a longo prazo & 3,70 & 3,46 & 4,45 & $-0,23$ & \multirow[t]{3}{*}{$-0,27$} \\
\hline & 30 & $\begin{array}{l}\text { Percebo oportunidades e adapto meu planejamento } \\
\text { para aproveitá-las }\end{array}$ & 3,57 & 3,63 & 4,00 & 0,05 & \\
\hline & 46 & $\begin{array}{l}\text { Busco desafios e sou motivado pela tríade } \\
\text { desafio-realização-reconhecimento }\end{array}$ & 4,13 & 4,05 & 4,20 & $-0,07$ & \\
\hline \multirow[t]{4}{*}{$\begin{array}{l}\text { Persuasão e } \\
\text { negociação }\end{array}$} & 9 & $\begin{array}{l}\text { Sou eficaz nas negociações e estabeleço } \\
\text { compromissos sustentáveis }\end{array}$ & 3,71 & 3,55 & 3,91 & $-0,16$ & \multirow[t]{4}{*}{$-0,66$} \\
\hline & 10 & $\begin{array}{l}\text { Consigo apoio às ideias por meio do } \\
\text { envolvimento de outras pessoas }\end{array}$ & 3,73 & 3,54 & 3,84 & $-0,20$ & \\
\hline & 11 & $\begin{array}{l}\text { Obtenho a colaboração das outras funções, para } \\
\text { assegurar o sucesso dos objetivos que proponho }\end{array}$ & 3,55 & 3,41 & 3,86 & $-0,14$ & \\
\hline & 12 & $\begin{array}{l}\text { Represento bem a organização ou área junto a } \\
\text { parceiros e outros públicos da organização }\end{array}$ & 4,36 & 4,20 & 4,25 & $-0,16$ & \\
\hline \multirow[t]{5}{*}{$\begin{array}{l}\text { Criatividade } \\
\text { e inovação }\end{array}$} & 18 & $\begin{array}{l}\text { Tenho ideias não convencionais, pensando } \\
\text { "fora da caixa" }\end{array}$ & 3,54 & 3,61 & 4,02 & 0,07 & \multirow[t]{5}{*}{0,04} \\
\hline & 19 & $\begin{array}{l}\text { Estou disposto a tentar novas soluções e sou } \\
\text { agente de mudança }\end{array}$ & 4,04 & 4,16 & 4,23 & 0,13 & \\
\hline & 20 & Encontro soluções novas para problemas comuns & 3,39 & 3,50 & 3,88 & 0,11 & \\
\hline & 21 & $\begin{array}{l}\text { Ajo como pioneiro (novos sistemas, serviços) na } \\
\text { busca de resultados para a organização }\end{array}$ & 3,39 & 3,36 & 3,88 & $-0,04$ & \\
\hline & 22 & $\begin{array}{l}\text { Penso em alternativas quando enfrento problemas } \\
\text { e formulo propostas de valor }\end{array}$ & 4,02 & 3,96 & 4,23 & $-0,05$ & \\
\hline \multirow[t]{4}{*}{ Trabalho em equipe } & 13 & $\begin{array}{l}\text { Estabeleço forte ligação com o time e sou bem } \\
\text { aceito pelo grupo }\end{array}$ & 4,32 & 4,00 & 4,52 & $-0,32$ & \multirow[t]{4}{*}{$-0,71$} \\
\hline & 14 & $\begin{array}{l}\text { Trabalho bem com o grupo, coopero na divisão de } \\
\text { ideias e recursos }\end{array}$ & 4,29 & 4,07 & 4,29 & $-0,21$ & \\
\hline & 42 & Pratico a empatia com colaboradores do meu time & 4,20 & 4,13 & 4,45 & $-0,07$ & \\
\hline & 43 & $\begin{array}{l}\text { Identifico a comunicação não verbal dos } \\
\text { colaboradores }\end{array}$ & 3,77 & 3,68 & 3,80 & $-0,09$ & \\
\hline \multirow[t]{3}{*}{$\begin{array}{l}\text { Autodesenvolvimento } \\
\text { e aprendizagem }\end{array}$} & 16 & $\begin{array}{l}\text { Sei trabalhar em rede e pratico o networking de } \\
\text { forma contínua }\end{array}$ & 3,59 & 3,54 & 4,21 & $-0,05$ & \multirow[t]{3}{*}{$-0,07$} \\
\hline & 36 & $\begin{array}{l}\text { Mantenho-me atualizado com conhecimentos } \\
\text { gerais não limitados à função }\end{array}$ & 4,09 & 4,05 & 4,32 & $-0,04$ & \\
\hline & 37 & $\begin{array}{l}\text { Busco ampliação do corpo de conhecimentos por } \\
\text { meio de cursos, seminários, estudos de outras línguas }\end{array}$ & 3,91 & 3,93 & 4,29 & 0,02 & \\
\hline \multirow[t]{3}{*}{ Carreira } & 38 & $\begin{array}{l}\text { Foco no desenvolvimento da carreira e na minha } \\
\text { empregabilidade }\end{array}$ & 3,82 & 3,89 & 4,32 & 0,07 & \multirow[t]{3}{*}{0,18} \\
\hline & 39 & $\begin{array}{l}\text { Identifico oportunidades de desenvolvimento e crio } \\
\text { diferenciação profissional }\end{array}$ & 3,57 & 3,57 & 4,09 & 0,00 & \\
\hline & 40 & $\begin{array}{l}\text { Pratico a reflexão sobre minha performance e atuação } \\
\text { e busco aprender a aprender }\end{array}$ & 4,05 & 4,16 & 4,38 & 0,11 & \\
\hline
\end{tabular}


Tabela 2 - Dados após análise fatorial - recomposição dos itens e identificação da variação das médias das percepções de uso dos atributos de competências

(Conclusão)

\begin{tabular}{|c|c|c|c|c|c|c|c|}
\hline Competências & Item & Atributo de competência & Estab. & Mud. & Import. & Delta & Fator \\
\hline \multirow{4}{*}{$\begin{array}{l}\text { Tomada de } \\
\text { decisão e solução } \\
\text { de problemas }\end{array}$} & 15 & Pratico a comunicação aberta, feedback e transparência & 4,30 & 4,09 & 4,66 & $-0,21$ & \multirow[t]{4}{*}{$-0,54$} \\
\hline & 23 & $\begin{array}{l}\text { Tomo decisões baseado em bom conhecimento da } \\
\text { área/função }\end{array}$ & 4,23 & 4,14 & 3,98 & $-0,09$ & \\
\hline & 24 & $\begin{array}{l}\text { Sou capaz de tomar decisões sob pressão (pouco } \\
\text { tempo, variáveis desconhecidas, risco) }\end{array}$ & 3,96 & 3,91 & 4,34 & $-0,05$ & \\
\hline & 25 & $\begin{array}{l}\text { Aproveito oportunidades no momento certo para } \\
\text { tomar decisões }\end{array}$ & 3,54 & 3,36 & 3,86 & $-0,18$ & \\
\hline \multirow[t]{3}{*}{ Personalidade } & 26 & $\begin{array}{l}\text { Trabalho bem com conceitos, atuando em "áreas } \\
\text { cinzentas" de situações complexas }\end{array}$ & 3,54 & 3,45 & 3,66 & $-0,09$ & \multirow[t]{3}{*}{$-0,24$} \\
\hline & 27 & Utilizo a intuição, além do julgamento racional & 3,41 & 3,39 & 3,45 & $-0,02$ & \\
\hline & 45 & $\begin{array}{l}\text { Sinto-me confortável em assumir riscos, buscando } \\
\text { maiores responsabilidades }\end{array}$ & 4,05 & 3,93 & 4,25 & $-0,13$ & \\
\hline \multirow[t]{4}{*}{$\begin{array}{l}\text { Determinação e } \\
\text { motivação }\end{array}$} & 32 & $\begin{array}{l}\text { Não sou rígido, sendo perseverante diante de } \\
\text { obstáculos }\end{array}$ & 3,95 & 3,91 & 3,88 & $-0,04$ & \multirow[t]{4}{*}{$-0,42$} \\
\hline & 33 & $\begin{array}{l}\text { Mantenho o otimismo, procuro tentar novamente } \\
\text { quando as coisas não dão certo }\end{array}$ & 4,13 & 3,96 & 4,11 & $-0,16$ & \\
\hline & 34 & $\begin{array}{l}\text { Faço dos obstáculos combustível para o } \\
\text { cumprimento das metas }\end{array}$ & 3,66 & 3,73 & 3,84 & 0,07 & \\
\hline & 35 & $\begin{array}{l}\text { Possuo um alto grau de dinamismo e motivação } \\
\text { pessoal }\end{array}$ & 4,16 & 3,89 & 4,45 & $-0,27$ & \\
\hline
\end{tabular}

Fonte: Dados da pesquisa.

\section{Análise dos resultados}

Como pode ser observado na Tabela 2 , há uma redução na prática da maioria dos atributos de competências, conforme a percepção do grupo de gestores. Contudo, para as competências "criatividade e inovação" e "carreira", a maioria dos gestores indica que há um aumento na utilização da maioria de seus atributos. O resultado indica que, em momentos de mudança, gestores são convocados a buscar soluções mais criativas e inovadoras para os problemas empresariais. Já quanto à competência "carreira", indica que gestores no contexto de mudanças põem em prática comportamentos para aumento da empregabilidade, fazendo da mudança uma oportunidade de desenvolvimento profissional. Por outro lado, as competências "trabalho em equipe", "persuasão e negociação" e "tomada de decisão" apresentaram maior diferença na média, indicando que, em contextos de mudança, os gestores se veem menos competentes nessas competências.
Complementarmente, na análise dos resultados há interesse em tentar validar as três hipóteses originalmente sugeridas no início deste estudo.

- Hipótese 1: há alteração na percepção dos gestores do conjunto de competências praticado entre as situações de estabilidade e mudança.

Os dados suportam essa hipótese, conforme pode ser observado no Gráfico 1. É possível observar que, para um grupo de gestores, a percepção da utilização dos atributos de competência na situação de mudança é maior do que na situação de estabilidade (18 respondentes), para dois deles não há diferença e, para os demais, há uma redução na utilização quando em uma situação de mudança, correspondendo a $64 \%$ do total (36 respondentes).

O resultado, auferindo que $64 \%$ dos respondentes se percebem menos competentes em situações de mudança, tem suporte na literatura e no modelo de Kolb (1997), indicando um processo de aprendizado 


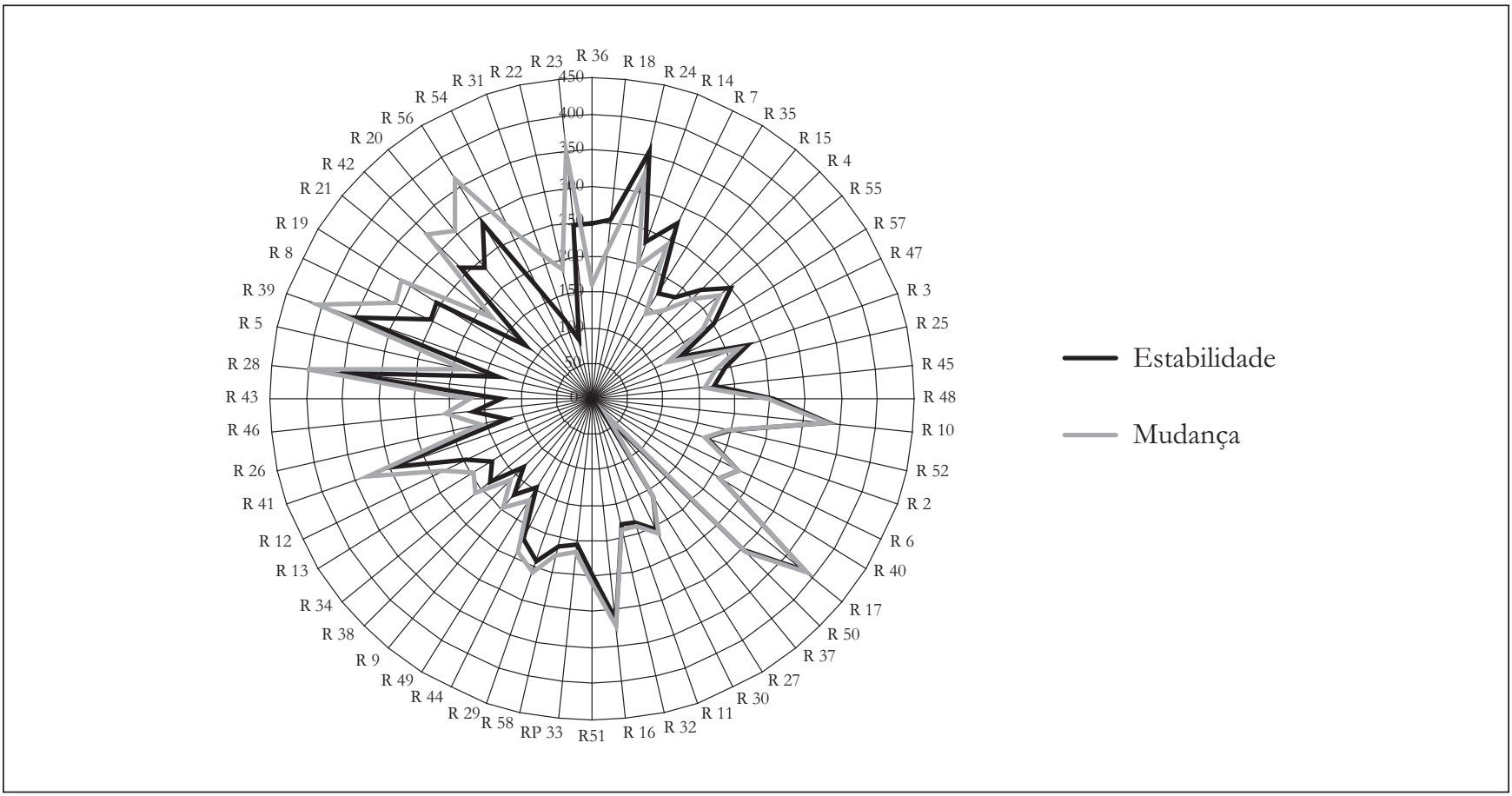

Gráfico 1 - Apresentação do GAP de competências entre situação de estabilidade e mudança organizacional Fonte: Dados da pesquisa.

e a consequente colocação em prática desses aprendizados, sendo um ciclo constante de busca pela eficácia ou aumento da própria competência.

- Hipótese 2: o nível de escolaridade é um dos fatores demográficos que influencia a percepção dos gestores.

A escolaridade neste estudo foi codificada como " 0 " para $3^{\circ}$ grau em andamento, " 1 " para $3^{\circ}$ grau completo e " 2 " para pós-graduados. A análise dos dados indica maior concentração de grau de escolaridade 2 para a amostra com GAP (diferença entre percepção de nível de competência na situação de mudança e estabilidade) menor do que zero. Contudo, faz-se necessária a comprovação estatística da influência dessa variável na percepção dos gestores sobre suas competências. Nesse caso, optou-se por rodar individualmente a regressão linear simples para cada uma das variáveis demográficas (variáveis independentes), tendo a variável dependente definida como o GAP do conjunto de competência (diferença entre mudança e estabilidade). Utilizando-se de regressão linear simples, nível de significância $p<0,05$, para a variável dependente "GAP" e variável independente "nível de escolaridade", foi possível observar que essa variável explica aproximadamente 14\% da variância total. Adicionalmente, pela análise do coeficiente Beta (negativo), conclui-se que quanto maior a escolaridade menor será o GAP do conjunto de competências entre mudança e estabilidade (mantendo-se as demais variáveis constantes). Dessa forma, a hipótese 2 é reforçada.

- Hipótese 3: a experiência gerencial é um fator de diferenciação na percepção do conjunto de competências nos dois contextos.

Para se tentar comprovar a hipótese 3, é preciso quantificar o GAP de competência de cada gestor e, para isso, usaremos uma sugestão de cálculo para o GAP de competências baseada no grau de importância médio dos respondentes e na perspectiva individual de cada item (CARBONE et. al., 2006, p. 68). Na comparação entre as duas amostras identificadas, divididas pelo critério de GAPs negativo e positivo, pode-se verificar que a média de experiência gerencial em anos das duas amostras é de 6,33 e 6,18, e o desvio-padrão de 5,26 e 4,68, respectivamente. Tais números não fortalecem a hipótese, por serem muito próximos e indicarem alta taxa de variância, porém, 
mesmo assim foi aplicada a regressão linear. Considerando a experiência gerencial como a variável independente e o conjunto de competências como a variável dependente, todavia não houve representatividade estatística, o que resulta na não confirmação da hipótese 3.

\section{Considerações finais}

O número de respondentes não propiciou uma análise simultânea de todos os 46 itens de atributos de competências, já que para isso seria necessária uma amostra de pelo menos 230 respondentes usando a relação de 5 medidas para cada variável (HAIR, 2006). Por isso a decisão de se avaliar os itens por meio de clusters tendo no máximo 11 itens, porém, entende-se que os resultados obtidos podem ser analisados e o modelo final dos 36 atributos de competências gerenciais pode ser utilizado como um modelo para estudos posteriores.

Apesar de reconhecer essas limitações, este estudo procurou identificar, na visão parcial, somente com a percepção dos próprios gestores sob si mesmos, a volatilidade da competência e a dificuldade de mantê-la sob condições novas, complexas e ou adversas. Para gestores, cujos desempenhos são medidos sistematicamente pela produção de resultados, na maioria das vezes no curto prazo, a agilidade na obtenção dos recursos (conhecimentos, experiências, práticas) que lhes permitam adaptar-se às mudanças e provar seu valor ou competência tem se tornado ainda mais desafiadora e seletiva. Esse parece ser um processo cíclico e contínuo e as referências de competências para o alto desempenho tendem a estar em níveis cada vez mais altos e dimensões mais complexas, tornando a busca da excelência gerencial uma estrada ainda mais longa, tortuosa e de poucos atalhos. Os modelos de competência, os instrumentos de medidas e as práticas de desenvolvimento devem considerar essa tendência sob pena de se tornarem obsoletos antes mesmo da sua total aplicação.

Pelas respostas dos gestores participantes deste estudo, as competências "criatividade e inovação" e "carreira" são praticadas de forma mais intensa em situações de mudança e as demais competências nas situações de estabilidade. Vale ressaltar a grande diferença nas competências "trabalho em equipe", "persuasão e negociação" e "tomada de decisão e solução de problemas", o que sugere que em momentos de mudanças os gestores, sob pressão, tendem a ser mais diretivos, ter limitação quanto à comunicação aberta e transparente, praticar menos o feedback e estabelecer menos ligação e envolvimento com o time. Questões relacionadas às necessidades pessoais dos membros do time, comunicação não verbal, empatia e coaching são menos presentes e o foco em atender resultados de curto prazo é priorizado. Infere-se aqui que, a partir da estabilização do contexto e do alcance de uma "zona de conforto", as práticas dos gestores tendem a fortalecer o time, transmitir a visão, reconhecer os resultados alcançados, estabelecer maior ligação com o grupo e planejar ações de mais longo prazo. Por outro lado, aparentemente, a criatividade e inovação e o foco na carreira são menos postos em prática.

Este trabalho, por meio de uma pesquisa exploratória, objetivou contribuir com os estudos em competências gerenciais e comprovar de maneira empírica que há variação no conjunto de competências postas em prática em contextos de estabilidade e mudança. Deve-se salientar que percepção é um critério subjetivo intrínseco a cada indivíduo, resultando em diferenças de entendimento e em uma grande diversidade de significados. Uma autoanálise não deve ser a única ferramenta para identificar as características na prática de um gestor. Há a necessidade da visão dos pares, dos subordinados e dos superiores para que essa "fotografia" instantânea seja a melhor representação da realidade, o que muitos autores indicam como avaliação $360^{\circ}$. A partir da escala final, obtida pela análise fatorial e o agrupamento dos 36 itens, abrem-se oportunidades de uso desse instrumento em novos estudos. Sugere-se a aplicação do questionário a grupos de gestores, mas ampliando a pesquisa para capturar as percepções dos superiores, dos pares e dos subordinados de forma a obter uma visão mais completa da realidade quanto às competências gerenciais nos diferentes contextos de estabilidade e mudança.

\section{Referências}

BONOTTO, F.; BITENCOURT, C. C. Os elementos das competências coletivas em grupos de trabalho a experiência da COPESUL. In: ENCONTRO DA ASSOCIACC̃̃ONACIONALDE PÓS-GRADUAÇ̃̃O E PESQUISA EM ADMINISTRAÇÃO - EnANPAD, 20., 2006, Salvador. Anais... Salvador: EnANPAD, 2006. 
BOWER, M. Talento para liderar. 2. ed. Rio de Janeiro: Campus, 1999.

BOYATZIS, R. E. The competent manager. 2nd ed. New York: John Wiley \& Sons, 1982.

CARBONE, P. P. Gestão por competências e gestão do conhecimento. 2. ed. Rio de Janeiro: FGV, 2006.

CHEETHAM, G.; CHIVERS, G. Towards a holistic model of professional competence. Journal of European Industrial Training, v. 11, n. 2, p. 28-39, 1996.

CHEETHAM, G.; CHIVERS, G. The reflective (and competent) practitioner: a model of professional competence which seeks to harmonise the reflective practitioner and competence-based approaches. Journal of European Industrial Training, v. 13, n. 3, p. 18-25, 1998.

DUTRA, J. S. (Org.). Gestão por competências. 2. ed. São Paulo: Gente, 2001.

FLEURY, A.; FLEURY, M. T. L. Estratégias empresariais e formação de competências. 2. ed. São Paulo: Atlas, 2006.

HAIR Jr., J. F. et al. Análise multivariada de dados. 2. ed. Porto Alegre: Bookman, 2006.

HUNT, J. W.; LAING, B. Leadership: the role of the exemplar. Business Strategy Review, v. 8, n. 1, p. 75-97, 1997.

KILIMNIK, Z. M.; SANT'ANNA, A. de S.; LUZ, T. R. Competências profissionais e modernidade organizacional: coerência ou contradição? Revista de Administração de Empresas, Minas Gerais, v. 44, p. 10-21, 2004. Edição Especial.

KLEMP Jr., O. G. Competências de liderança. HSM Management, São Paulo, v. 3, n. 17, p. 128-144, 1999.

KOLB, D. A. A gestão e o processo de aprendizagem. In: STARKEY, K. (Org.). Como as organizações aprendem: relatos do sucesso das grandes empresas. 2. ed. São Paulo: Futura, 1997. p. 321-341.

LE BOTERF, G. Competénce et navigation profissionnelle. 2e éd. Paris: d'Organisatio, 1999.

LE BOTERF, G. Desenvolvendo a competência dos profissionais. 2. ed. Porto Alegre: Artmed, 2003.

McLAGAN, P. A. "Competencies". Training and Development. American Society for Training and Development, New York, v. 51, n. 5, p. 40-47, 1997.
McCLELLAND, D. C. Testing for competence rather than intelligence. American Psychologist, New York, v. 28, n. 1, p. 27-39, 1973.

McGREGOR, J.; TWEED, D. Facing the challenge of improving managerial competence in small business: the New Zealand experience. Presentation at The 31st European Small Business Seminar. Dublin: Dublin Institute of Technology, 2001.

ODERICH, L. C. Gestão de competências gerenciais: noções e processos de desenvolvimento em três empresas gaúchas. 2001.151 f. Dissertação (Mestrado em Administração) - Universidade Federal do Rio Grande do Sul, Porto Alegre, 2001.

PRAHALAD, C. K.; HAMEL, G. A competência essencial da corporação. In: ULRICH, D. (Org.). Recursos humanos estratégicos. 2. ed. São Paulo: Futura, 2000. p. 79-101.

ROBOTHAM, D.; JUBB, R. Competences: measuring the unmeasurable. Management Development Review, Bradford, v. 9, n. 5, p. 6-19, 1996.

RUAS, R. Gestão por competências: uma contribuição à estratégia das organizações. In: RUAS, R.; ANTONELLO, C. S.; BOFF, L. H. (Org.). Aprendizagem organizacional e competências. 2. ed. Porto Alegre: Bookman, 2005. p. 34-54.

SCHEIN, E.H. Organizational culture and leadership. 2nd ed. San Francisco, CA: Sage, 1992.

SCHEIN, E. H. Guia de sobrevivência da cultura corporativa. Rio de Janeiro: José Olympio, 2007.

WINTERTON, J.; WINTERTON, R. Developing managerial competence. London; New York: Routledge, 1999.

ZARIFIAN, P. Objective competence. 2nd ed. Liasson: Paris, 1999.

ZARIFIAN, P. Objetivo competência: por uma nova lógica. 2. ed. São Paulo: Atlas, 2001

Recebido: 24/08/2010 Received: 08/24/2010

Aprovado: 09/11/2010 Approved: 11/09/2010 


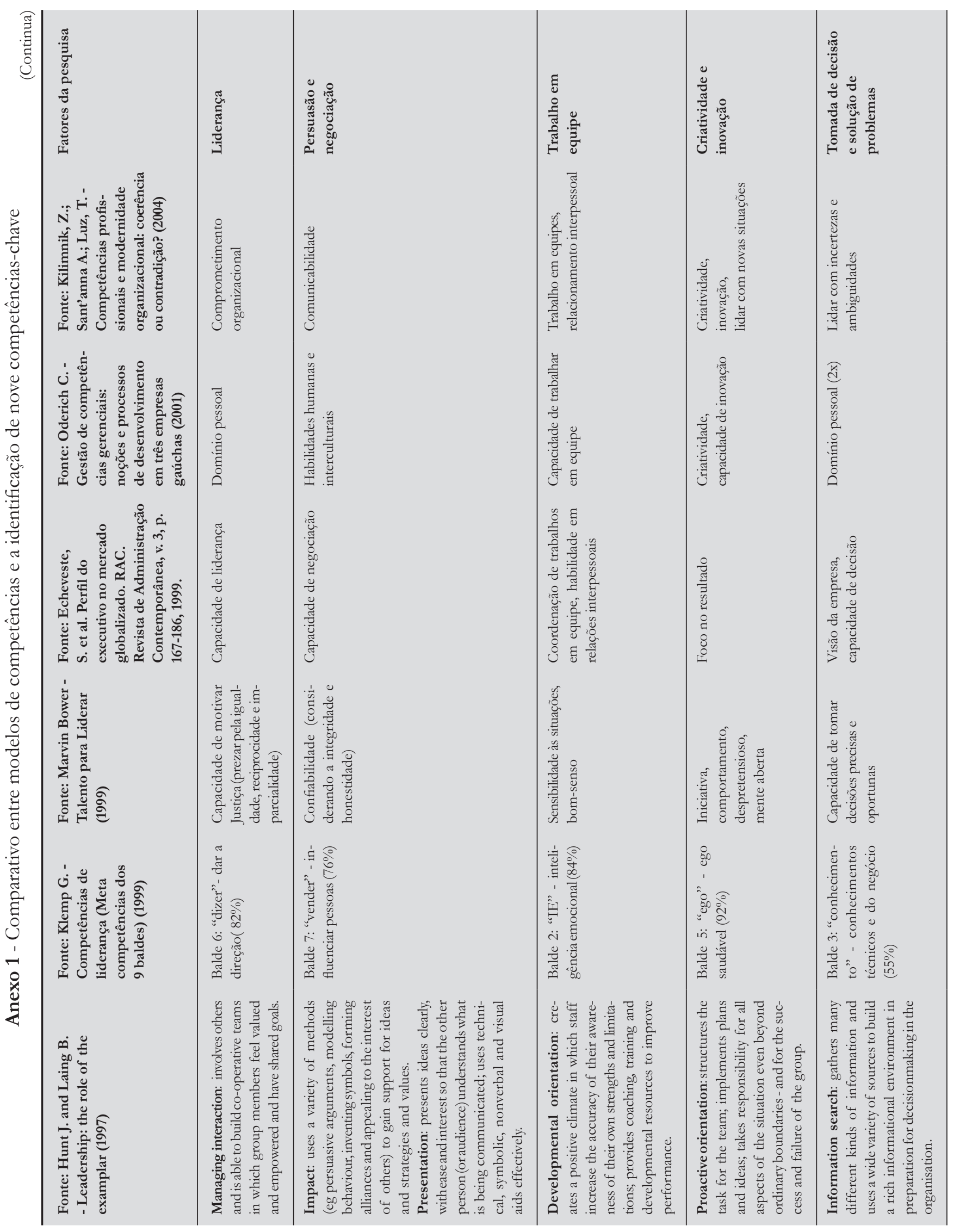




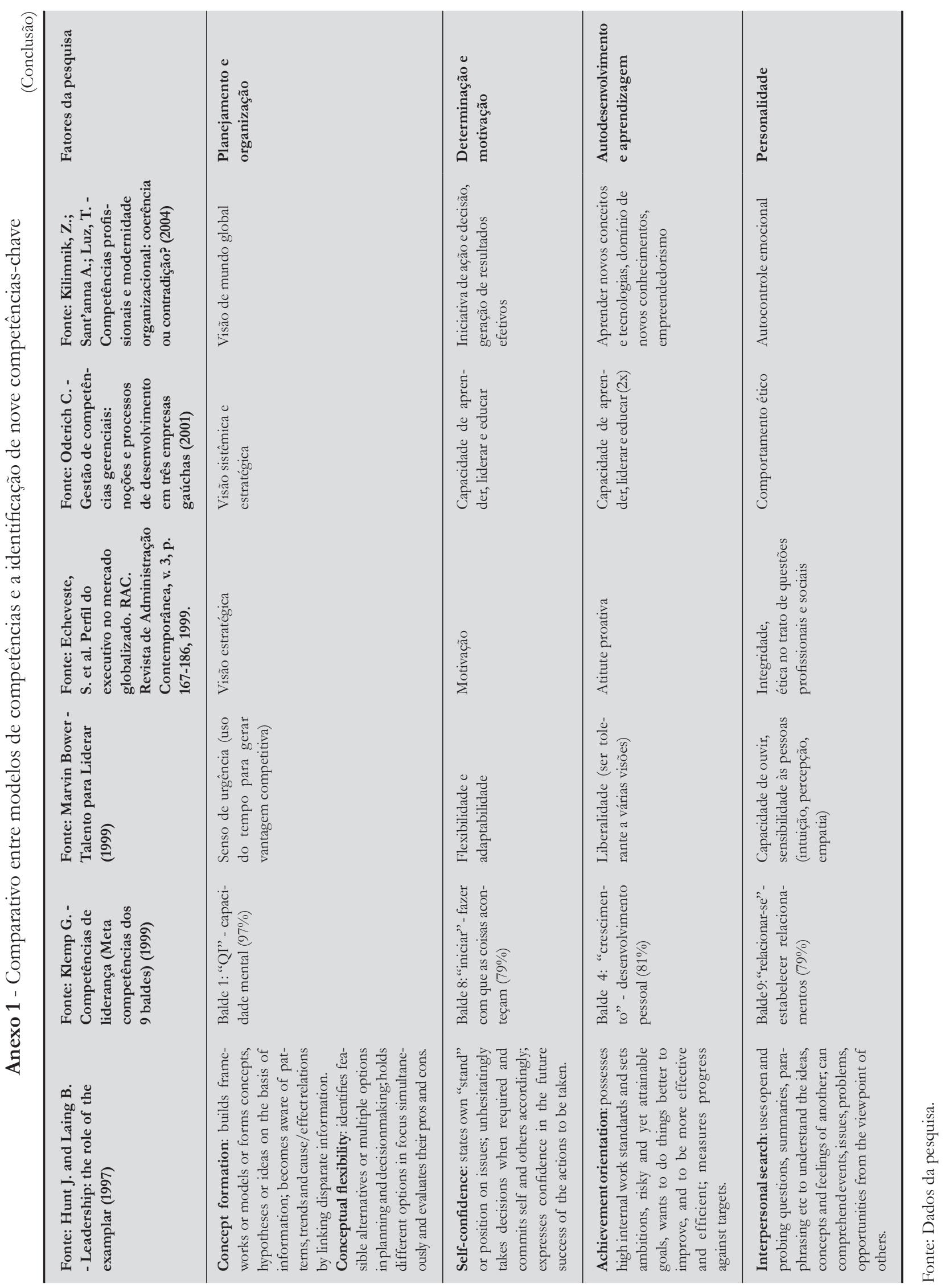


Anexo 2 - Questionário dos dados demográficos

Instrução para o preenchimento. Leia com bastante atenção (tempo estimado de resposta: 30 minutos):

1) Este trabalho tem objetivo puramente acadêmico, suas respostas individuais não serão compartilhadas.

2) Ao término do trabalho, o consolidado dos dados será disponibilizado aos respondente como feedback.

3) Não existem respostas certas ou erradas, o que importa é a sua percepção.

4) No campo verde-claro (situação de estabilidade), pense nos momentos de tranquilidade em seu setor e indique com um $\mathrm{X}$ sua percepção de como você aje para cada um dos itens.

5) No campo em amarelo (situação de mudanças), pense nos momentos de mudanças em seu setor e indique com um $\mathrm{X}$ sua percepção de como você aje para cada um dos itens.

6) No campo em roxo, você deverá indicar o grau de importância de cada item (de 1 a 5 em ordem crescente de importância).

7) Por favor, preencha todas as linhas.

\section{Dados do pesquisado}

1) Formação: curso e escolaridade (ex.: Administração de Empresas ou Engenharia)

2) Formação complementar: (ex.: Administração de Empresas ou pós-graduação)

3) Idade:

4) Tempo de empresa (em anos):

5) Experiência gerencial (em anos):

6) Quantidade de subordinados diretos (hierarquia direta, incluindo terceiros):

7) Quantidade de subordinados indiretos (hierarquia indireta, incluindo terceiros):

8) Área de atuação (service, PMP, canal indireto, vendas, marketing, etc.):

9) Local de atuação (regional ou área central):

Para você, quais são suas principais competências?

Fonte: Dados da pesquisa. 


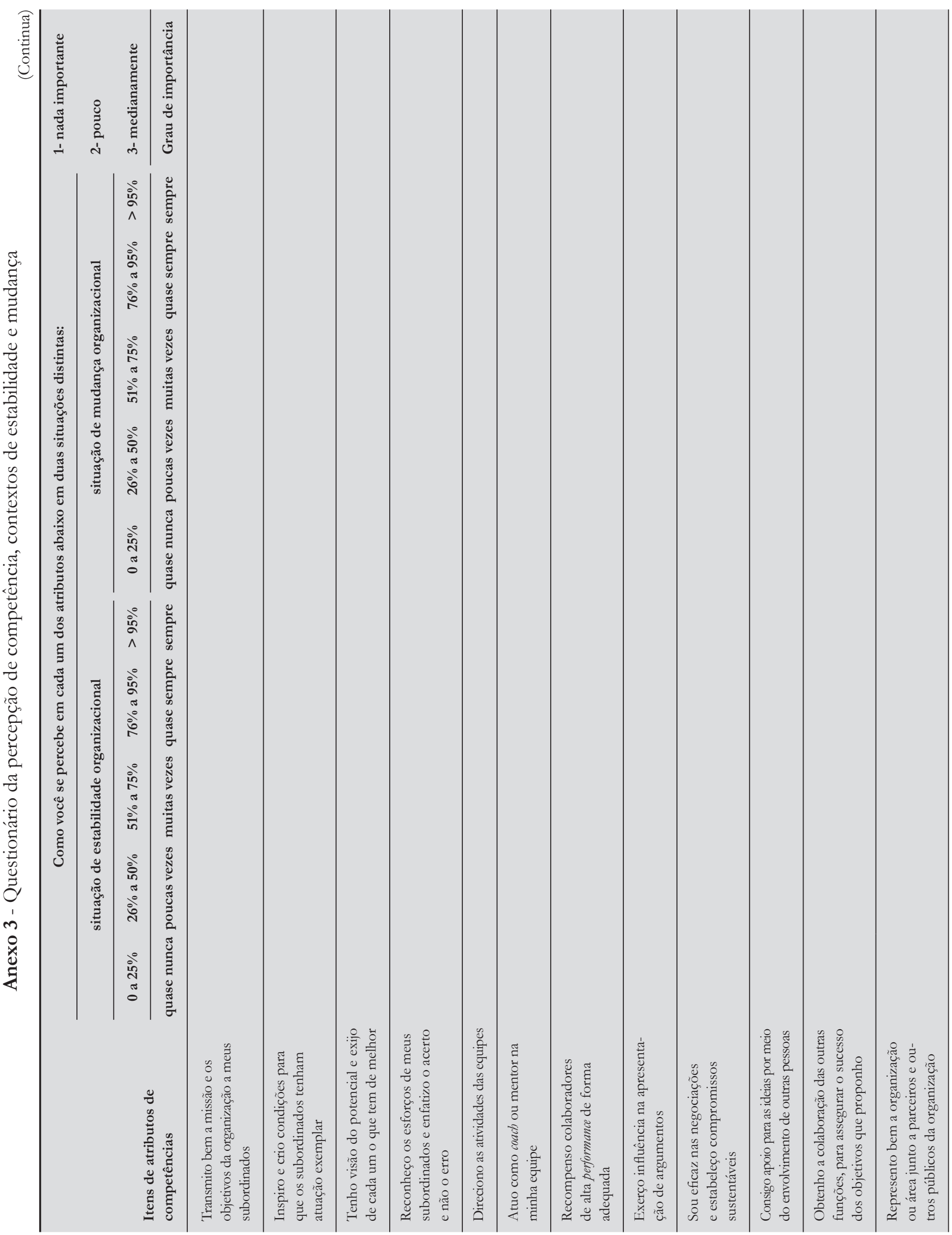




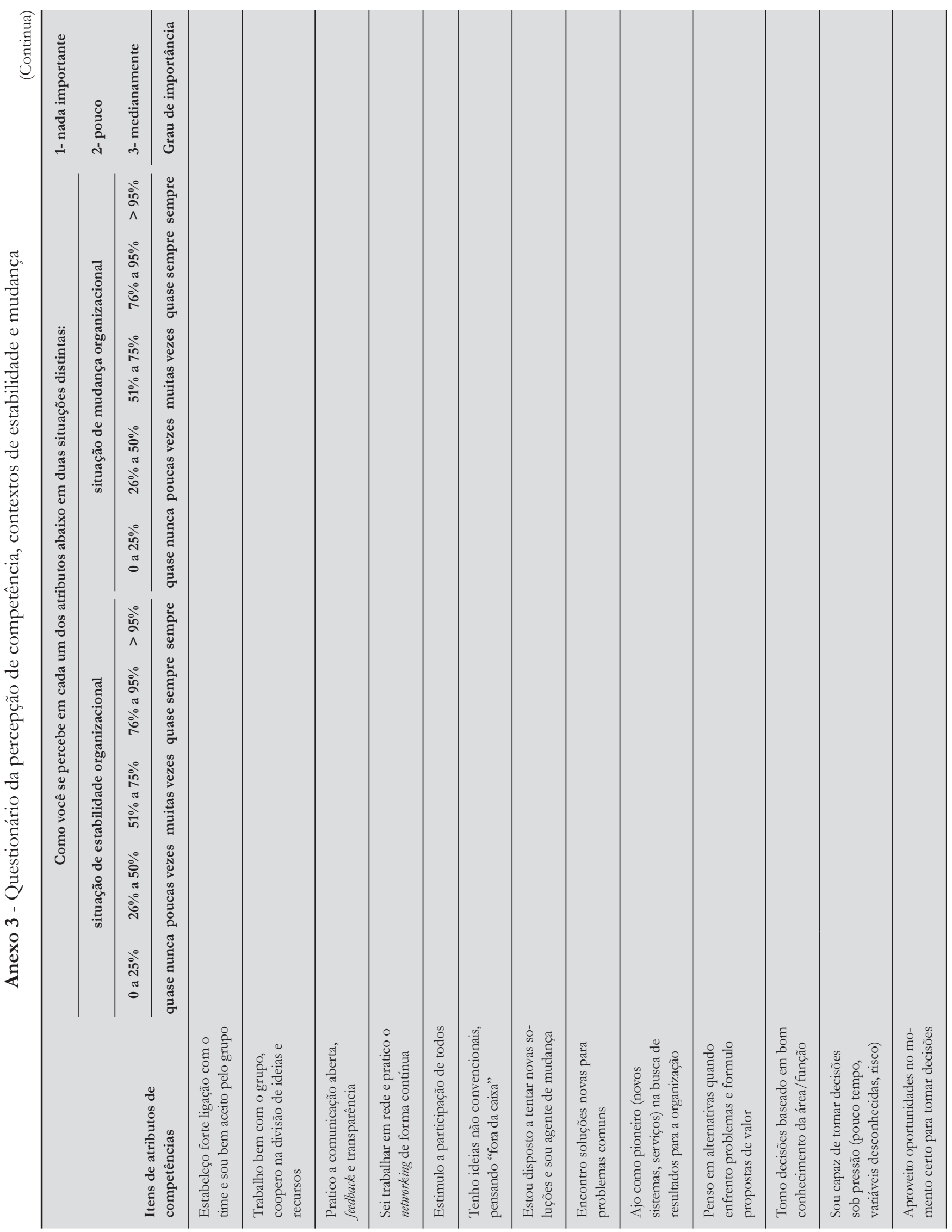




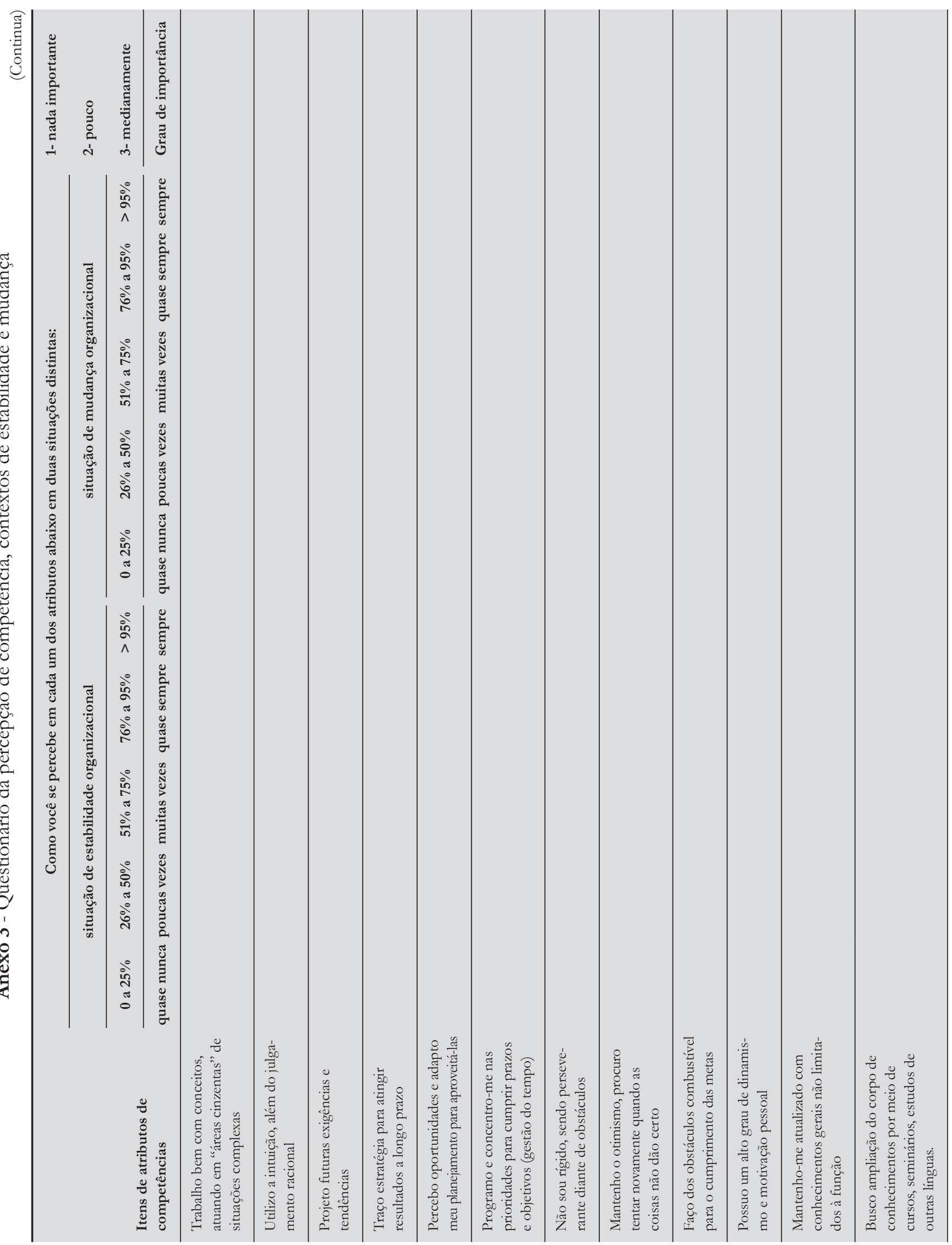




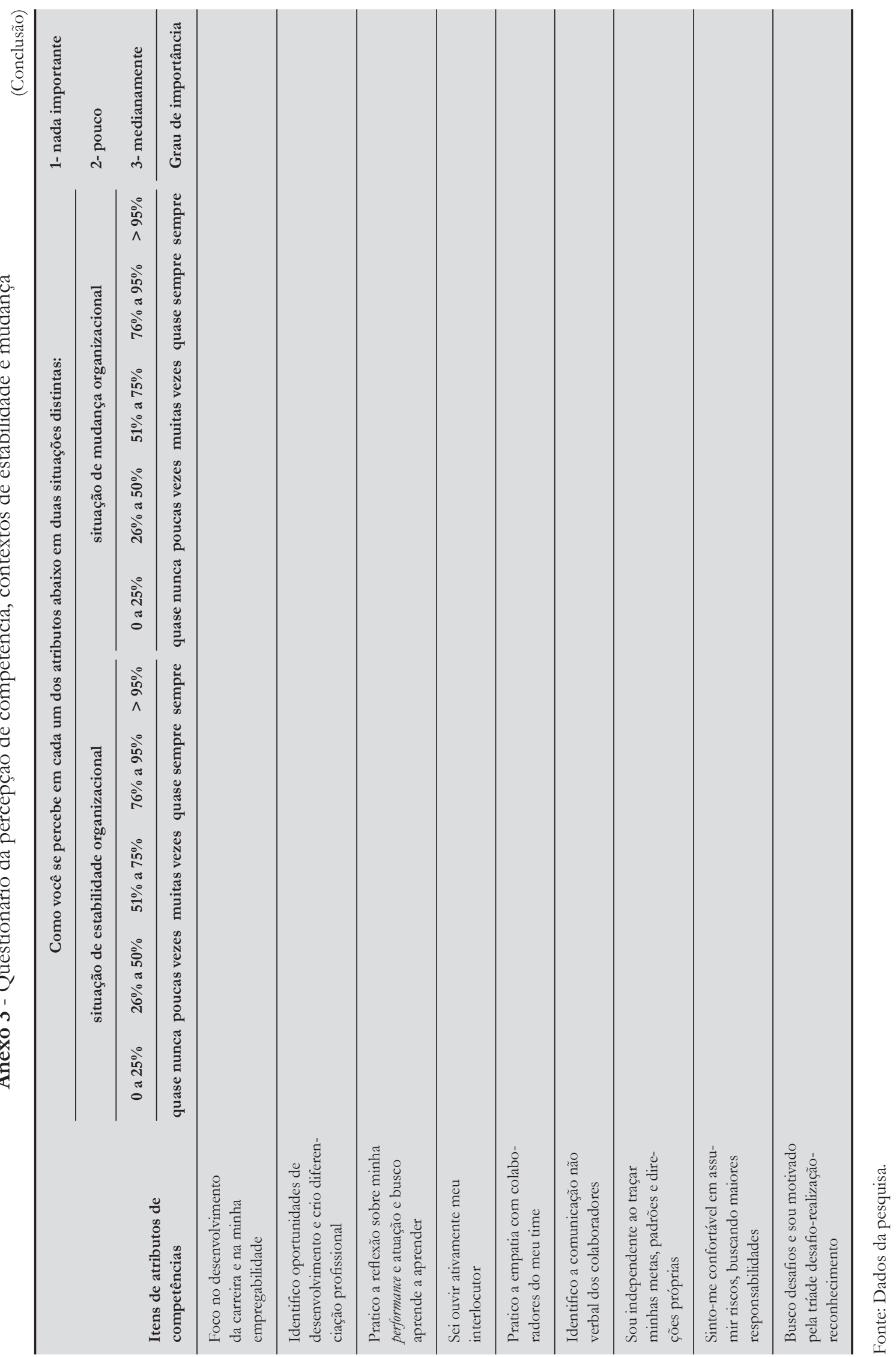

